(2) Open Access Full Text Article

ORIGINAL RESEARCH

\title{
Impact of Intraoperative Ocular Lubricants on Corneal Debridement Rate During Vitreoretinal Surgery
}

This article was published in the following Dove Press journal:

Clinical Ophthalmology

Michael L Mathison'

Albert S Li (D)

Yicheng $\mathrm{K}$ Bao $\mathbb{D}^{2}$

Andrew JW Huang (D)

Rithwick Rajagopal (D)

'Department of Ophthalmology and Visual Sciences, Washington University School of Medicine, Saint Louis, MO 63II0, USA; ${ }^{2}$ Department of Medicine, University of Missouri - Kansas City School of Medicine, Kansas City, MO 64II2, USA
Correspondence: Rithwick Rajagopal Washington University School of Medicine, Campus Box 8096, 660 South Euclid Avenue, Saint Louis, MO 63II0, USA

Tel +I 3143626929

$\mathrm{Fax}+$ I 3|4-362-2420

Email rajagopalr@wustl.edu
Purpose: To compare surgical parameters among patients receiving Viscoat (sodium chondroitin sulfate $4 \%$-sodium hyaluronate $3 \%$ ) or Goniosol (hydroxypropyl methylcellulose $2.5 \%$ ) as topical lubricants for retinal surgery.

Methods: This was a retrospective analysis of patients undergoing retinal surgery between March 2013 and March 2018 using Goniosol or Viscoat as adjuvants. Primary outcome measures were rate of corneal debridement and operative time between groups, compared using $\chi^{2}$ and $t$-tests, respectively.

Results: Compared to Viscoat $(n=319)$, the Goniosol group $(n=210)$ had more frequent intraoperative corneal debridement $(21.4 \%$ vs $0, p<0.05)$ and longer surgical times (98 vs 78 minutes, $p<0.05$ ). Patients in the Viscoat group had higher rates of complex procedures ( $34.8 \%$ vs $26.7 \%, p<0.05$ ), but were younger (50.7 vs 55.0 years, $p<0.05$ ) and more likely to be phakic $(83.4 \%$ vs $70.5 \%, p<0.05)$.

Conclusion: These findings suggest potential advantages of using Viscoat over Goniosol for corneal lubrication to aid visualization during vitreoretinal surgery.

Keywords: corneal epithelium, corneal debridement, corneal edema, Goniosol, Viscoat, vitreoretinal surgery

\section{Introduction}

Recent advances in vitreoretinal surgery, e.g., smaller-gauge instrumentation and highspeed vitreous cutters, have made procedures safer and more effective. However, intraoperative loss of corneal transparency remains a source of frustration for vitreoretinal surgeons, and is an important cause of surgical complications. Once corneal edema develops, surgeons often restore their view of the retina by mechanically debriding the corneal epithelium. Beyond extending operative time, corneal debridement is associated with a number of postoperative morbidities, including postoperative pain due to persistent epithelial defect and risk of corneal ulceration, infection, and/or scarring. ${ }^{1}$

Ocular lubricants applied intermittently to the surface of the eye during surgery mitigate the loss of corneal integrity and prevent the need for epithelial debridement. Though balanced salt solutions may be suited for this purpose, viscous lubricants are preferred, because they provide a longer effect. Various lubricants designed for other ophthalmic applications have been repurposed for preserving corneal clarity during vitreoretinal surgery. In a comparison of two such agents, Garcia-Vasquez et al found that use of GenTeal (Alcon Laboratories, Fort Worth, TX) as a corneal lubricant 
resulted in a decreased need for epithelial debridement compared to a more traditional agent - Goniosol (Akorn Pharmaceuticals, Lake Forest, IL). ${ }^{2}$ However, GenTeal may also cause serious ocular toxicity, ${ }^{3}$ especially in patients with large conjunctival incisions. ${ }^{4}$ Furthermore, because it is has not been approved for intraoperative use, we have experienced significant regulatory barriers, preventing our own use of GenTeal in the operating room during vitreoretinal procedures. Viscoat (Alcon Laboratories) is a dispersive viscoelastic agent commonly used in various intraocular procedures and readily available in ophthalmic operating rooms. ${ }^{5}$ Its safety for topical and intraocular use is well documented. In this study, we compared surgical outcomes using Viscoat compared to Goniosol for corneal lubrication in vitreoretinal procedures.

\section{Methods}

Study protocols were approved by the Washington University Human Research Protection Office and the Institutional Review Board (IRB ID 201804089) in compliance with Health Insurance Portability and Accountability Act guidelines and the tenets of the Declaration of Helsinki. Patient consent to review their medical records was not required for this study, because data extraction was deemed no more than minimal risk to the privacy of individuals, as determined by the Washington University Human Research Protection Office. Team members ensured that patient identifiers were not improperly used or disclosed throughout the course of the study. Consecutive adult patients undergoing vitreoretinal surgery by a single surgeon (RR) between March 2013 and March 2015 and March 2016 and March 2018 were included. There were no changes in operating-room staff or equipment over the period of the study.

Patients in the initial time frame were uniformly treated with sterile Goniosol, whereas those in the latter time frame were given only Viscoat. Both agents were applied to the cornea at the beginning of the surgery and reapplied as needed. Patients undergoing surgery during the 1-year interval between these time frames were not included because they could not readily be assigned to one study group or another, since the surgeon transitioned between the two adjuvants during this period. Patients undergoing combined surgery (anterior segment and posterior segment) were excluded, as were patients with known pre existing corneal disease. All vitrectomy cases were performed using a noncontact viewing system (Binocular Indirect Ophthalmomicroscope; Oculus Surgical, Port Saint Lucie, FL). Scleral buckling was also performed with a noncontact system (indirect ophthalmoscope). We reviewed operative notes on all patients to record operating time and to determine whether or not corneal debridement had been performed during each case. Baseline demographic information, including medical history and phakic status, was recorded, along with type of surgery based on Current Procedural Terminology (CPT) codes with confirmation by operative notes.

For statistical analyses, data are represented as means \pm SEM. Parametric values were compared using Student's $t$-test. Categorical variables were compared using $\chi^{2}$ or Fisher's exact tests when appropriate. When appropriate, correction for multiple comparisons was performed using Bonferroni's post hoc test. A two-tailed $p$-value of $<0.05$ was considered significant. All data were analyzed using SAS 9.4 (SAS Institute, Cary, NC).

\section{Results}

In total, 210 patients receiving Goniosol and 319 receiving Viscoat during vitreoretinal surgery were included in the final analysis. Although groups were assigned chronologically, rather than randomly, indications for surgery were similar between groups (Table 1). Rhegmatogenous retinal detachment was the most common indication for surgery in

Table I Indications for Surgery Within Cohorts

\begin{tabular}{|l|l|l|l|l|}
\hline & $\begin{array}{l}\text { Total } \\
\text { Cohort }\end{array}$ & Goniosol & Viscoat & p-value \\
\cline { 2 - 5 } & $\mathbf{n}(\%)$ & $\mathbf{n}(\%)$ & $\mathbf{n}(\%)$ & $\left(\chi^{2}\right)$ \\
\hline All indications & 555 & 219 & 336 & \\
Proliferative diabetic & $67(12.1)$ & $30(14.2)$ & $37(11.0)$ & 0.34 \\
retinopathy & & & & \\
Endophthalmitis & $9(1.6)$ & $5(2.4)$ & $4(1.2)$ & 0.32 \\
Uninfectious & $3(0.5)$ & $2(1.0)$ & $1(0.3)$ & 0.33 \\
inflammation & & & & \\
\hline Retinal detachment & $270(48.6)$ & $106(50.2)$ & $164(51.4)$ & 0.93 \\
$\quad$ Rhegmatogenous & $206(37.1)$ & $89(42.2)$ & $117(34.8)$ & 0.17 \\
$\quad$ Tractional & $55(9.9)$ & $14(6.6)$ & $41(12.2)$ & 0.03 \\
Serous & $9(1.6)$ & $3(1.4)$ & $6(1.8)$ & 0.70 \\
\hline Retinal defect & $6(1.1)$ & $2(1.0)$ & $4(1.2)$ & 0.76 \\
Vein occlusion & $3(0.5)$ & $1(0.5)$ & $2(0.6)$ & 0.83 \\
Macular hole & $28(5.1)$ & $9(4.3)$ & $19(5.7)$ & 0.42 \\
ERM & $45(8.1)$ & $13(6.2)$ & $32(9.5)$ & 0.13 \\
Vitreous hemorrhage & $92(16.6)$ & $33(15.6)$ & $59(17.6)$ & 0.44 \\
Trauma & $5(0.9)$ & $4(1.9)$ & $1(0.3)$ & 0.06 \\
IOL complication & $17(3.1)$ & $9(4.3)$ & $8(2.4)$ & 0.25 \\
Retained lens & $10(1.8)$ & $5(2.4)$ & $5(1.5)$ & 0.49 \\
fragment/subluxed lens & & & & \\
\hline
\end{tabular}

Notes: Data represented as number in each group followed by column percentages in parentheses.

Abbreviation: IOL, intraocular lens. 
both groups, with vitreous hemorrhage being the secondmost common. Notably, tractional retinal detachments were more common in the Viscoat group. Baseline demographics for the two groups were largely similar, with no differences in sex breakdown or rates of hypertension and diabetes (Table 2). However, there were notable differences: mean age in the Goniosol group was greater than in the Viscoat cohort (55 vs 50.7 years, $p<0.05$ ), and the Goniosol group had more pseudophakes $(29.5 \%$ vs $16.6 \%, p<0.05)$. The Viscoat cohort contained a higher proportion of complex retinal detachment repairs and membrane peels, but a lower proportion of vitrectomies with endolaser photocoagulation and a lower proportion of retinal detachment repairs by vitrectomy (Table 2).

In the Goniosol group, corneal epithelial debridement was performed intraoperatively in $21.4 \%$ of cases (Table 3 ). In contrast, there were no instances of corneal debridement in the Viscoat group $(p<0.025)$. Corneal debridement was more commonly performed when using Goniosol for vitrectomy, vitrectomy with endolaser, retinal detachment repairs by vitrectomy, or complex retinal detachment repairs (Table 3). However, no differences in debridement rates were seen in simple membrane-peeling maneuvers or in scleral buckling procedures using either agent.

Finally, mean surgical times in the Goniosol group were significantly longer than procedures utilizing Viscoat when considering all procedures examined (98 minutes vs 78 minutes; $p<0.025)$. Although the compositions of the two groups were different, the expected average operative time for the Goniosol group and Viscoat group was similar (86.3 minutes vs 85.3 minutes). Differences in operative time between groups were most pronounced in retinal detachment repairs utilizing vitrectomy and in complex retinal detachment cases (Table 4). However, a significantly decreased operating time was also observed among vitrectomy with endolaser cases when using Viscoat compared to Goniosol.

\section{Conclusion}

This retrospective analysis of operative records from a single surgeon working in an academic setting shows reduced rates of corneal debridement during vitreoretinal

Table 2 Cohort Demographics

\begin{tabular}{|c|c|c|c|c|c|c|c|}
\hline & $\begin{array}{l}\text { Total } \\
\text { Cohort }\end{array}$ & Goniosol & Viscoat & p-value & $\begin{array}{l}\text { Corneal } \\
\text { Debridement }\end{array}$ & $\begin{array}{l}\text { No Corneal } \\
\text { Debridement }\end{array}$ & p-value \\
\hline $\begin{array}{l}\text { n } \\
\text { Mean age, years (SEM) } \\
\text { Males (\%) }\end{array}$ & $\begin{array}{l}529 \\
52.4(20.6) \\
323(61.1)\end{array}$ & $\begin{array}{l}210 \\
55.0(16.1) \\
131(62.4)\end{array}$ & $\begin{array}{l}319 \\
50.7(22.9) \\
192(60.2)\end{array}$ & $\begin{array}{l}\mathbf{0 . 0 1} \\
0.61\end{array}$ & $\begin{array}{l}45(8.55) \\
51.1(18.8) \\
33(73.3)\end{array}$ & $\begin{array}{l}484(91.5) \\
52.6(20.8) \\
290(59.9)\end{array}$ & $\begin{array}{l}0.65 \\
0.078\end{array}$ \\
\hline $\begin{array}{l}\text { Lens status } \\
\text { Phakic } \\
\text { Pseudo/aphakic }\end{array}$ & $\begin{array}{l}414(78.3) \\
115(21.7)\end{array}$ & $\begin{array}{l}148(70.5) \\
62(29.5)\end{array}$ & $\begin{array}{l}266(83.4) \\
53(16.6)\end{array}$ & 0.0004 & $\begin{array}{l}31(68.9) \\
14(31.1)\end{array}$ & $\begin{array}{l}383(79.1) \\
101(20.9)\end{array}$ & 0.11 \\
\hline $\begin{array}{l}\text { Systemic disease } \\
\text { Diabetes } \\
\text { Hypertension }\end{array}$ & $\begin{array}{l}148(28.0) \\
124(23.4)\end{array}$ & $\begin{array}{l}56(26.7) \\
31(19.5)\end{array}$ & $\begin{array}{l}92(28.8) \\
83(26.0)\end{array}$ & $\begin{array}{l}0.59 \\
0.08\end{array}$ & $\begin{array}{l}\text { II (24.4) } \\
8(17.8)\end{array}$ & $\begin{array}{l}137(28.3) \\
116(24.0)\end{array}$ & $\begin{array}{l}0.58 \\
0.35\end{array}$ \\
\hline $\begin{array}{l}\text { Surgery type (CPT codes) } \\
\text { Vitrectomy (66852 and } \\
67036)\end{array}$ & $78(\mid 4.7)$ & $26(12.4)$ & $52(16.3)$ & 0.21 & $4(8.9)$ & $74(15.3)$ & 0.25 \\
\hline $\begin{array}{l}\text { Vitrectomy w/endolaser } \\
\text { (67039 and 67040) }\end{array}$ & $65(12.3)$ & $40(19.1)$ & $25(7.8)$ & 0.0001 & $8(17.8)$ & $57($ (II.8) & 0.24 \\
\hline $\begin{array}{c}\text { Membrane peel } \\
(6704 I \text { and } 67042)\end{array}$ & $115(2 \mid .7)$ & $31(14.8)$ & $84(26.3)$ & 0.0016 & $0(0)$ & $115(23.8)$ & $<0.0001$ \\
\hline Scleral buckling (67/07) & $25(4.7)$ & $12(5.7)$ & $13(4.1)$ & 0.38 & $2(4.4)$ & $23(4.8)$ & 0.93 \\
\hline $\begin{array}{l}\text { RD repair by vitrectomy } \\
(67108)\end{array}$ & $79(14.9)$ & $45(21.4)$ & $34(10.7)$ & 0.0007 & $15(33.3)$ & $64(13.2)$ & 0.0003 \\
\hline $\begin{array}{l}\text { Complex RD repair } \\
(67 \mid 13)\end{array}$ & $167(31.6)$ & $56(26.7)$ & III (34.8) & 0.049 & $16(35.6)$ & $|5|(3 \mid .2)$ & 0.55 \\
\hline
\end{tabular}

Notes: Data represented as number in each group, followed by column percentages in parentheses unless otherwise indicated. Mean age in each group compared using twotailed $t$-tests; all other comparisons used $\chi^{2}$. Values noted in bold significant.

Abbreviations: RD, retinal detachment; CPT, current procedural terminology. 
Table 3 Intraoperative Corneal Epithelium-Debridement Rates

\begin{tabular}{|c|c|c|c|}
\hline & $\begin{array}{l}\text { Corneal } \\
\text { Debridement }\end{array}$ & $\begin{array}{l}\text { No corneal } \\
\text { Debridement }\end{array}$ & $p$-value \\
\hline $\begin{array}{l}\text { Lubricant } \\
\text { Goniosol }(n=2 \mid 0) \\
\text { Viscoat }(n=3 \mid 9)\end{array}$ & $\begin{array}{l}45(21.4) \\
0(0)\end{array}$ & $\begin{array}{l}165(78.6) \\
319(100)\end{array}$ & $<0.0001$ \\
\hline Surgery type & & & \\
\hline $\begin{array}{c}\text { Vitrectomy } \\
\text { Goniosol } \\
\text { Viscoat }\end{array}$ & $\begin{array}{l}4 \\
0\end{array}$ & $\begin{array}{l}22 \\
52\end{array}$ & 0.0037 \\
\hline $\begin{array}{l}\text { Vitrectomy w/ } \\
\text { endolaser } \\
\text { Goniosol } \\
\text { Viscoat }\end{array}$ & $\begin{array}{l}8 \\
0\end{array}$ & $\begin{array}{l}32 \\
25\end{array}$ & 0.017 \\
\hline $\begin{array}{l}\text { Membrane peel } \\
\text { Goniosol } \\
\text { Viscoat }\end{array}$ & $\begin{array}{l}0 \\
0\end{array}$ & $\begin{array}{l}31 \\
84\end{array}$ & NA \\
\hline $\begin{array}{l}\text { Scleral buckling } \\
\text { Goniosol } \\
\text { Viscoat }\end{array}$ & $\begin{array}{l}2 \\
0\end{array}$ & $\begin{array}{l}10 \\
13\end{array}$ & 0.12 \\
\hline $\begin{array}{c}\text { RD repair by } \\
\text { vitrectomy } \\
\text { Goniosol } \\
\text { Viscoat }\end{array}$ & $\begin{array}{l}15 \\
0\end{array}$ & $\begin{array}{l}30 \\
34\end{array}$ & 0.0002 \\
\hline $\begin{array}{l}\text { Complex RD } \\
\text { repair } \\
\text { Goniosol } \\
\text { Viscoat }\end{array}$ & $\begin{array}{l}16 \\
0\end{array}$ & $\begin{array}{l}40 \\
111\end{array}$ & $<0.0001$ \\
\hline
\end{tabular}

Notes: Data represented as number in each group, and groups compared using $\chi^{2}$. Values noted in bold significant.

surgeries using Viscoat compared to Goniosol as a topical lubricating agent. Furthermore, operating times were shorter in cases using Viscoat compared to Goniosol, despite the Viscoat group containing a significantly more complex case mix. These results suggest that use of Viscoat provides better retention of corneal clarity during vitreoretinal surgeries, allowing for more rapid accomplishment of surgical goals.

There are several important caveats to this study. First, the Viscoat group was on average about 5 years younger than the Goniosol group (55.0 vs 50.7 years, $p<0.05$ ). A higher proportion of younger eyes with healthier corneal tissue may partly account for our observed reductions in corneal debridement rates among Viscoat patients. There were also more pseudophakes in the Goniosol group than the Viscoat group $(29.5 \%$ vs $16.6 \%, p<0.05)$. Therefore, in the Goniosol group, we may have included more patients with higher risk of endothelial loss during retinal surgery, due to endothelial cell compromise from prior cataract surgery. ${ }^{6}$ In terms of both of these caveats, differences in baseline demographics were expected, given the nonrandomized nature of the group allocation used in our study. However, we observed no differences in mean age (51.1 vs 52.6 years, $p=0.65$ ) among Goniosol patients who required corneal debridement versus those who avoided debridement, and rates of corneal debridement were comparable for phakic and pseudophakic patients (20.9 vs $22.5 \%$, respectively; $p>0.79$ ), observations to be expected if these factors are not the major drivers of need for corneal debridement. It is also worthwhile noting that we observed zero instances of corneal debridement in the Viscoat group, suggesting a real and profound improvement in lubricating capability between this agent and Goniosol for maintaining intraoperative corneal health, despite other differences in groups. Given these caveats, the retrospective nature of our study design, and the confounders introduced by the temporal separation between study groups, our results do not prove efficacy of one agent over the other in the setting of visualization during retinal surgery. Instead, they provide a rationale for prospectively evaluating the comparative efficacy of these agents.

Table 4 Surgical Times Within Cohorts by Procedure Performed

\begin{tabular}{|l|l|l|l|l|}
\hline \multirow{2}{*}{ Surgery Type (CPT Codes) } & Total Cohort & Goniosol & Viscoat \\
\cline { 2 - 5 } & Time, Minutes (SEM) & Time, Minutes (SEM) & Time, Minutes (SEM) \\
\hline All types & $86(42.6)$ & $98(47.0)$ & $78(37.4)$ & $<2(36.1)$ \\
Vitrectomy (66852 and 67036) & $66(39.5)$ & $75(44.9)$ & $71(40.2)$ & $<0.00001$ \\
Vitrectomy with endolaser (67039 and 67040) & $86(49.1)$ & $96(51.9)$ & $62(22.6)$ & 0.18 \\
Membrane peel (6704I and 67042) & $64(23.2)$ & $82(23.8)$ & $84(17.4)$ & 0.03 \\
Scleral buckling (67I07) & $86(21.4)$ & $96(25.6)$ & $65(19.2)$ & 0.057 \\
RD repair by vitrectomy (67108) & $83(34.6)$ & $128(49.3)$ & $103(39)$ & $\mathbf{0 . 0 0 1 6}$ \\
Complex RD repair (67II3) & $111(44.2)$ & 0.0001 \\
\hline
\end{tabular}

Notes: Data presented as number in each group, followed by column percentages. Groups compared using two-tailed t-tests. Values noted in bold significant. 
Table 5 Ingredients in Goniosol and Viscoat

\begin{tabular}{|l|l|l|l|}
\hline Lubricant & Active Ingredient(s) & Inactive Ingredient(s) & Preservative(s) \\
\hline $\begin{array}{l}\text { Goniosol } \\
\text { (Akorn) }\end{array}$ & $\begin{array}{l}\text { Hypromellose 2906, 25 mg } \\
(2.5 \%)\end{array}$ & $\begin{array}{l}\text { Boric acid, edetate disodium, potassium chloride, sodium borate, purified water. } \\
\text { hydrochloric acid and/or sodium hydroxide may be added to adjust pH (6.0-7.8) }\end{array}$ & $\begin{array}{l}\text { Benzalkonium } \\
\text { chloride 0.01\% }\end{array}$ \\
\hline $\begin{array}{l}\text { Viscoat } \\
\text { (Alcon) }\end{array}$ & $\begin{array}{l}\text { Sodium hyaluronate (3\%), } \\
\text { chondroitin sulfate (4\%) }\end{array}$ & None & None \\
\hline
\end{tabular}

Although we attribute our observed difference in surgical times between the two cohorts (98 [Goniosol] vs 78 [Viscoat] minutes, $p<0.05$ ) to improved retinal viewing offered by Viscoat, it is also possible that the Goniosol group contained a disproportionate number of cases requiring longer operating times. However, in favor of our interpretation of these results, the Viscoat group had a higher proportion of complex retinal detachment cases (CPT 67113) than the Goniosol group ( $34.8 \%$ vs $26.7 \%, p<0.05)$.

Several factors could account for our observations of improved corneal clarity during retinal procedures using Viscoat compared to Goniosol. First, Goniosol solution contains many more additives (inactive ingredients) than Viscoat (Table 5). Among these additives, the preservative benzalkonium chloride has been known to be toxic to the corneal epithelium. Benzalkonium chloride is commonly contained in anti-glaucoma medications and is linked to the worsening of the ocular surface seen with chronic use of these medications. ${ }^{7}$ Second, Viscoat is hyperosmolar relative to the cornea $(325 \mathrm{mOsm} / \mathrm{kg}$ vs $305 \mathrm{mOsm} / \mathrm{kg}$, respectively), and this property may lead to reduced fluid accumulation within the cornea. ${ }^{8}$ Finally, Viscoat's rheological property as an ocular viscoelastic device may be a salient factor explaining our observations. ${ }^{5}$ The dispersive nature of Viscoat allows its effective coating of the corneal endothelium during phacoemulsification. These dispersive properties may similarly increase its effectiveness as an epithelial protectant.

A previous prospective study showed GenTeal is an effective alternative to Goniosol, with slower declines in corneal clarity during vitreoretinal surgery. ${ }^{2}$ In that study, the overall debridement rate was lower in the GenTeal Group (14\%) than the Goniosol group (54\%) among a total cohort of 71 patients. Our study was not prospective, and we did not compare GenTeal to Viscoat, but it is noteworthy that we observed no instances of corneal debridement in the Viscoat group in a cohort of 319 patients. Despite the positive results in surgical parameters we report in this study, the increase in cost of Viscoat to Goniosol may be unappealing to some vitreoretinal surgeons. Further studies could investigate the use of less costly alternatives with physical characteristics similar to Viscoat for vitreoretinal surgery.

\section{Ethical Approval}

The Washington University Institutional Review Board (201804089) approved this study.

\section{Funding}

NIH/NEI EY025269 (RR), NIH/NEI EY002687

(Washington University Depertment of Ophthalmology and Visual Sciences), NIH/NIDDK T32DK007120 (YKB), Career Development Award from Research to Prevent Blindness (RR), an Unrestricted Award from Research to Prevent Blindness (Washington University Department of Ophthalmology and Visual Sciences), Horncrest Foundation Support (RR), UMKC School of Medicine Sarah Morrison Research Award (YKB).

\section{Disclosure}

The authors report no conflicts of interest in this work.

\section{References}

1. McGrath LA, Lee GA. Techniques, indications and complications of corneal debridement. Surv Ophthalmol. 2014;59:47-63. doi:10.1016/j. survophthal.2013.03.004

2. Garcia-Valenzuela E, Abdelsalam A, Eliott D, et al. Reduced need for corneal epithelial debridement during vitreo-retinal surgery using two different viscous surface lubricants. Am J Ophthalmol. 2003;136:1062-1066. doi:10.1016/S0002-9394(03)00634-2

3. Burugapalli K, Koul V, Dinda AK. Effect of composition of interpenetrating polymer network hydrogels based on poly(acrylic acid) and gelatin on tissue response: a quantitative in vivo study. $J$ Biomed Mater Res. 2004;68:210-218. doi:10.1002/jbm.a.10117

4. Dalvin LA, Garcia MD, Salomao DR, et al. Necrotizing subconjunctival granulomata and intraoperative use of topical genteal gel. Ophthalmology. 2016;123:2262-2263. doi:10.1016/j.ophtha.2016.05. 040

5. Van den Bruel A, Gailly J, Devriese S, et al. The protective effect of ophthalmic viscoelastic devices on endothelial cell loss during cataract surgery: a meta-analysis using mixed treatment comparisons. $\mathrm{Br}$ J Ophthalmol. 2011;95:5-10. doi:10.1136/bjo.2009.158360

6. Takkar B, Jain A, Azad S, et al. Lens status as the single most important factor in endothelium protection after vitreous surgery: a prospective study. Cornea. 2014;33:1061-1065. doi:10.1097/ ICO.0000000000000218 
7. Goldberg I, Graham SL, Crowston JG, et al. Clinical audit examining the impact of benzalkonium chloride-free anti-glaucoma medications on patients with symptoms of ocular surface disease. Clin Experiment Ophthalmol. 2015;43:214-220. doi:10.1111/ ceo.12431
8. McCannel CA. Improved intraoperative fundus visualization in corneal edema: the Viscoat trick. Retina. 2012;32:189-190. doi:10.1097/ IAE.0B013E318232AE26

\section{Publish your work in this journal}

Clinical Ophthalmology is an international, peer-reviewed journal covering all subspecialties within ophthalmology. Key topics include: Optometry; Visual science; Pharmacology and drug therapy in eye diseases; Basic Sciences; Primary and Secondary eye care; Patient Safety and Quality of Care Improvements. This journal is indexed on PubMed

Submit your manuscript here: https://www.dovepress.com/clinical-ophthalmology-journal
Central and CAS, and is the official journal of The Society of Clinical Ophthalmology (SCO). The manuscript management system is completely online and includes a very quick and fair peer-review system, which is all easy to use. Visit http://www.dovepress.com/ testimonials.php to read real quotes from published authors. 